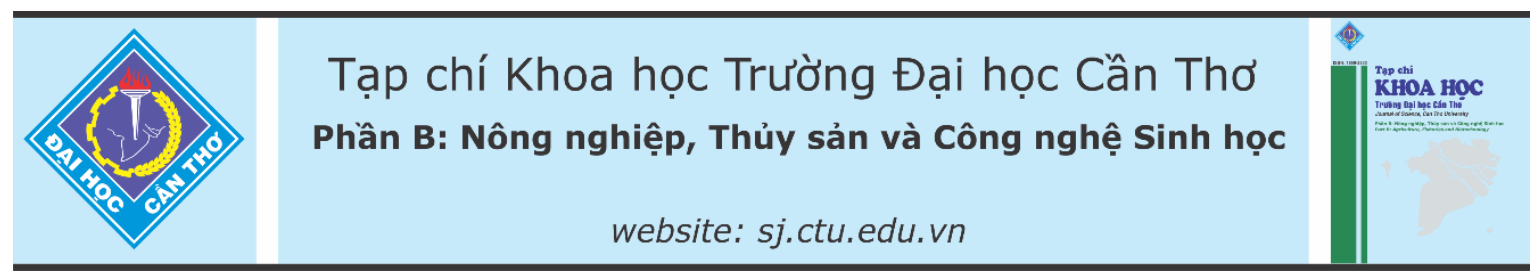

DOI:10.22144/ctu.jvn.2021.154

\title{
HIỆU QUẢ CỦA DỊCH TRÍCH THỰC VẠTT ĐỐI VỚI NẨM Curvularia sp. GÂYY BỆNH VẾT NÂU TRÊN LÚA
}

\author{
Lê Thanh Toàn ${ }^{1 *}$ và Nguyễn Hòa $\mathrm{Nam}^{2}$ \\ ${ }^{1}$ Khoa Nông nghiệp, Truờng Đại học Cần Tho' \\ ${ }^{2}$ Sinh viên ngành Bảo vệ Thực vật K41, Truoòng Đại học Cần Tho \\ *Nguoòi chịu trách nhiệm về bài viết: Lê Thanh Toàn (email: lttoan@ctu.edu.vn)
}

\section{Thông tin chung:}

Ngày nhận bài: $27 / 04 / 2021$

Ngày nhận bài sưa: 13/08/2021

Ngày duyệt đăng: 29/10/2021

Title:

Efficacy of plant extracts against Curvularia sp. causing brown leaf spot on rice plants

\section{Tù khóa:}

Cây lúa, Curvularia sp., dịch trich thực vật

\section{Keywords:}

Curvularia sp., plant extract, rice

\begin{abstract}
Curvularia sp. is one of the most important fungal pathogens causing damages on rice leaves and grains, leading to losses of rice yield. Based on this context, research was carried out to find out an effective and safe method on managing Curvularia. Results of surveying diversity of conidia and appressoria of Curvularia showed that four kinds of conidia were $Y$ shaped, oval, cuneiform, fusiform; as well as three types of fungal appressoria were claviform, oval, elliptical with the wavy margin. Average conidial size range from 4.5-11.5 x 3.5-5.2 $\mu \mathrm{m}$. Among three extracts of garlic, wrinkled-leaf mint, ginger with concentration of $2 \%$, the extracts of garlic and ginger had high efficacy against hyphal development of Curvularia sp in vitro test. However, the garlic extract was better than ginger one on maintaining inhibiting efficacy. Under net house conditions, foliar sprays with garlic extract at one day before or after pathogen inoculation showed a disease reduction at approximately 86.62 and $87.97 \%$, respectively, equivalent to positive control $(150 \mathrm{~g} / \mathrm{L}$ Difenoconazole $+150 \mathrm{~g} / \mathrm{L}$ Propiconazole) .
\end{abstract}

\section{TÓM TẮT}

Nấm Curvularia sp. là một trong nhũng tác nhân quan trọng gây hại tán lá và hạt lúa, làm giảm năng suất. Do đó, nghiên cưu được thưc hiện nhằm tìm ra biện pháp hiệu quả, an toàn trong việc quản lí Curvularia. Kết quả khảo sát sụ đa dạng bào tư và đĩa áp của các chủng nấm Curvularia ghi nhận bốn dạng bào tư hình chĩu $Y$, hình trứng, thẳng nhọn một đầu, hình tru đỉnh cùn; và ba dạng đĩa áp hình chùy, hình trứng, dạng xẻ thùy. Kích thuoóc bào tử trung bình là 4,5-11,5 x 3,5-5,2 $\mu \mathrm{m}$. Trong ba loại dịch trích gồm tỏi, húng quế, gùng với nồng độ $2 \%$, dịch trích tỏi và gùng cho hiệu quả ức chế in vitro sự phát triển khuẩn ty nấm Curvularia $s p$. Tuy nhiên, dịch trích tỏi tốt hơn dịch trích gùng trong việc duy trì hiệu quả ức chế. Trong điều kiện nhà luới, việc xủ lí dịch trích tỏi tại thời điểm I ngày truớc và sau khi lây bệnh cho hiệu quả giảm bệnh so với đối chưng, lần lượt là $86,62 \%$ và $87,97 \%$, cao tuơng đương nghiệm thức đối chứng duong (150 g/L Difenoconazole $+150 \mathrm{~g} /$ L Propiconazole).

\section{GIỚI THIỆU}

Việt Nam là một quốc gia nông nghiệp và đã đạt được nhiều thành tựu nổi bật. Sản xuất nông nghiệp đã mang lại sự tăng trưởng đáng kể về kinh tế cho nước ta. Với điều kiện thuận lợi về khí hậu, thổ nhưỡng, Đồng bằng sông Cửu Long luôn chiếm vị trí hàng đầu về nông nghiệp, đặc biệt là lĩnh vực sản 
xuất lương thực. Khu vực này đứng đầu về xuất khẩu gạo với tỉ trọng khoảng $60 \%$ tổng sản lượng lương thực và $90 \%$ lượng gạo xuất khẩu của cả nước (Nguyễn Ngọc Đệ, 2008; Tổng cục Thống kê, 2020). Trong canh tác theo hướng truyền thống như thâm canh, tăng vụ, việc sử dụng thuốc hóa học liên tục vẫn chiếm tỉ trọng cao (Lê Văn Cương và ctv., 2018). Điều này dẫn đến việc gia tăng nguy cơ bùng phát các loại dịch hại nghiêm trọng, làm giảm năng suất và chất lượng lúa. Hơn nữa, khí hậu nhiệt đới ở Đồng bằng sông Cửu Long cũng góp phần tạo điều kiện thuận lợi cho sự phát sinh, phát triển của các loại nấm gây bệnh, trong đó có nấm Curvularia sp. Bệnh vết nâu do Curvularia sp. là một trong các bệnh gây hại quan trọng ở các quốc gia trồng lúa trên thế giới, trong đó có Việt Nam (Akhsan et al., 2019; Lê Thanh Toàn \& Thị Sử, 2020; Ortega et al., 2020; Tann \& Soytong, 2016).

Trong giai đoạn hội nhập quốc tế, việc sản xuất lương thực theo hướng an toàn đang được quan tâm. Một trong những biện pháp mới là ứng dụng dịch trích thực vật trong kiểm soát bệnh hại. Một số nghiên cứu sử dụng dịch trích thực vật quản lý bệnh hại đã được thực hiện. Nguefack et al. (2008) cho biết ba loại tinh dầu chiết xuất từ cây sả, hương nhu trắng và hoa môi có khả năng chống lại sự xâm nhiễm của Alternaria padwickii, Bipolaris oryzae và Fusarium moniliforme gây bệnh trên hạt lúa. Ba loại tinh dầu này còn giúp tăng độ nảy mầm của hạt giống và giúp cây lúa sinh trưởng tốt hơn. Phan Thị Hồng Thúy (2009) đã ghi nhận khi ngâm hạt với dịch trích cây sống đời (Kalanchoe pinnata (Lam.) Pers), cỏ cứt heo (Ageratum conyzoides L.) hay áo hạt bằng dịch trích cỏ cứt heo, các nghiệm thức đều có hiệu quả với bệnh đốm nâu do $B$. oryzae, trong đó hai nghiệm thức ngâm hạt với cỏ cứt heo $4 \%$ cho hiệu quả giảm bệnh (HQGB) trên $50 \%$. Hạt lúa ngâm từ dịch trích củ tỏi và lá cây hoàng anh giúp hạt giống nảy mầm tốt và giảm đáng kể sự xuất hiện của các loại nấm trên hạt lúa như $B$. oryzae, Curvularia oryzae, Nigrospora oryzae, Aspergillus flavus, Aspergillus niger (Yeasmin et al., 2012). Như vậy, nghiên cứu hiệu quả dịch trích thực vật đối với bệnh vết nâu lúa do Curvularia $\mathrm{sp}$. vẫn chưa nhiều. Vì thế, nghiên cứu đã được thực hiện nhằm khảo sát đặc điểm bào tử và đĩa áp nấm Curvularia sp., chọn ra loại và nồng độ dịch trích thực vật có hiệu quả trong việc kiểm soát nấm Curvularia sp. gây bệnh vết nâu trên lúa trong điều kiện in vitro và nhà lưới.

\section{VÂT LIỆU VÀ PHƯƠNG PHÁP}

\subsection{Giống lúa và loại dịch trích}

Giống lúa nhiễm Jasmine 85 và năm chủng nấm Curvularia được cung cấp từ phòng thí nghiệm Phòng trừ Sinh học, Bộ môn Bảo vệ Thực vật, Khoa Nông nghiệp, Trường Đại học Cần Thơ. Trước khi tiến hành nghiên cứu, nhiều loại dịch trích thực vật ở các nồng độ khác nhau đã được đánh giá nhanh ảnh hưởng đến sự nảy mầm của bào tử Curvularia sp. Từ kết quả sơ khởi này, dịch trích củ tỏi (Allium sativum L.) $2 \%$, húng quế (Ocimum basilicum $\mathrm{L}$.) $2 \%$ và củ gừng (Zingiber offcinale Rose) $2 \%$ được chọn để thực hiện các thí nghiệm trong nghiên cứu này.

2.2. Khảo sát các dạng, kích thước bào tử, dạng đĩa áp và đánh giá tính độc của các chủng nấm Curvularia

Thí nghiệm được bố trí hoàn toàn ngẫu nhiên (HTNN) với 3 lần lặp lại trên 5 chủng nấm Curvularia. Thí nghiệm sử dụng phương pháp nuôi cấy trên lam (Wijedasa \& Liyanapathirana, 2012) để quan sát và ghi nhận hình dạng, kích thước của bào tử, hình dạng đĩa áp. Một khoanh môi trường PDA có đường kính $8 \mathrm{~mm}$ và dày $3 \mathrm{~mm}$ được đặt lên lam đã được thanh trùng. Nấm Curvularia sp. được cấy vào bốn bên của khoanh môi trường và đậy lamelle lại. Sau đó, tất cả được đặt vào đĩa petri có chứa 2,5 $\mathrm{mL}$ nước cất vô trùng có giấy thấm để giữ ẩm, trong đĩa petri có chứa 2 que cây để kê lam. Mẫu được ủ trong 5 ngày, sau đó chuyển lamelle sang một lam khác để quan sát. Quan sát mẫu dưới kính hiển vi quang học bằng dung dịch Cotton blue. Kích thước bào tử được đo 20 lần ở mỗi lặp lại của một nghiệm thức. Chỉ tiêu theo dõi bao gồm hình dạng, kích thước bào tử và hình dạng đĩa áp.

Các nguồn nấm được lây bệnh nhân tạo trên cây lúa 20 ngày tuổi để đánh giá nhanh và chọn ra chủng nấm mang độc tính cao nhất để thực hiện thí nghiệm tiếp theo. Thí nghiệm bố trí với 5 nghiệm thức, 4 lặp lại, 2 cây lúa/lặp lại, đánh dấu lá 5 và 6 của mỗi cây lúa. Sau khi nuôi cấy 10 ngày, bào tử nấm Curvularia sp. được phun lên các cây lúa với lượng $3 \mathrm{~mL} /$ chậu với mật số 50.000 bào tử $/ \mathrm{mL}$, có thêm $0,2 \%$ Tween 20 . Các chậu sau khi phun huyền phù nấm được để trong phòng lây bệnh nhân tạo, ủ 24 giờ trong tối, $25^{\circ} \mathrm{C}$, ẩm độ khoảng $95 \pm 3 \%$. Sau đó, các chậu lúa được chuyển ra nhà phun sương, 30 phút/lần phun, che mát $50 \%$ nhằm giúp cho bệnh phát triển (Elamawi \& El-Shafey, 2013). Diện tích nhiễm bệnh $\left(\mathrm{mm}^{2}\right)$ (công thức 1$)$, tỉ lệ diện tích lá nhiễm bệnh (\%) (công thức 2 ) của lá 5 và 6 được ghi nhận ở 7 ngày sau lây bệnh (NSLB). 


$$
S i=\sum(s 0 a 0+s 1 a 1+\ldots+s 5 a 5)
$$

Trong đó, $S_{\mathrm{i}}(\mathrm{i}=0-5)$ : diện tích vết bệnh cấp $\mathrm{i}, \mathrm{a}_{\mathrm{i}}$ (i = 0-5): số vết bệnh thứ i;

$$
\text { TLDTLNBj }=(S j / S) \times 100 \%
$$

Trong đó, $S_{\mathrm{j}}(\mathrm{j}=5-6)$ : tổng diện tích lá nhiễm bệnh thứ $\mathrm{j}, \mathrm{S}$ : diện tích lá, được tính $\mathrm{S}=$ dài * rộng * 0,75 (Liu et al., 2016).

\section{3. Đánh giá hiệu quả của dịch trích (HQDT) thực vật đối với nấm Curvularia trong điều kiện in vitro}

Thí nghiệm được bố trí theo thể thức HTNN gồm 4 nghiệm thức là dịch trích củ tỏi $2 \%$, dịch trích húng quế $2 \%$, dịch trích củ gừng $2 \%$ và đối chứng, 4 lần lặp lại. Nghiệm thức đối chứng là môi trường PDA không có chứa dịch trích.

Nguồn nấm Curvularia sp. (mang độc tính cao) được nuôi cấy trong đĩa petri khoảng 10 ngày trước khi tiến hành thí nghiệm. Khuẩn ty nấm sẽ được đục thành các khoanh có đường kính khoảng $5 \mathrm{~mm}$ khi thực hiện thí nghiệm.

Mẫu thực vật sau khi thu về được rửa sạch bằng nước cất và để khô tự nhiên (khoảng 12-14 ngày). Cụ thể, thực vật khô được nghiền mịn bằng chày và cối, thêm nước cất, rồi chưng cách thủy ở $62^{\circ} \mathrm{C}$ trong 15 phút, khuấy đều. Sau đó, $50 \mathrm{~mL}$ môi trường PDA được nấu tan. Khi môi trường đạt nhiệt độ khoảng $55-60^{\circ} \mathrm{C}$ thì cho thêm dịch trích hoặc nước cất thanh trùng vào chai, lắc chai môi trường để hòa tan đều vào môi trường. Sau đó, môi trường trong chai được bơm vào các đĩa petri bằng Dispenser với lượng 10 $\mathrm{mL}$ môi trường/đĩa petri. Sau khi môi trường đặc lại, các khoanh khuẩn ty nấm Curvularia sp. đã chuẩn bị được đặt vào chính giữa đĩa petri. Các đĩa petri thí nghiệm được đặt ở nhiệt độ phòng (Elamawi \& El-Shafey, 2013). Đường kính khuẩn lạc của nấm đã được ghi nhận vào các thời điểm $1,3,5$ ngày sau đặt khoanh khuẩn ty (NSĐKT). HQDT được xác định bằng công thức (3).

$$
H Q D T(\%)=\left[\left(\nexists K K L_{d c}-Ð K K L_{d t}\right) / \nexists K K L_{d c}\right] \times 100 \%
$$

Trong đó, $\mathrm{DKKL}_{\text {đc }}$ là đường kính khuẩn lạc của nghiệm thức đối chứng nước cất $(\mathrm{mm}), \mathrm{DKKL}_{\mathrm{tt}}$ là đường kính khuẩn lạc của nghiệm thức dịch trích (mm) (Atlas, 2010).

Ở thời điểm ghi nhận chỉ tiêu cuối cùng, ba khoanh khuẩn ty nấm (đường kính $5 \mathrm{~mm}$ ) ở ba góc của rìa của khuẩn ty được thu và cho vào ống nghiệm chứa $10 \mathrm{~mL}$ nước cất thanh trùng, vortex thật kỹ. Dung dịch huyền phù gốc được pha loãng 100 lần, rồi đếm số lượng bào tử nấm bằng lam đếm hồng cầu để xác định mật số bào tử nấm. Thí nghiệm đánh giá hiệu quả và xác định số lượng bào tử nấm được thực hiện lặp lại ba lần.

\section{4. Đánh giá HQDT thực vật đối với bệnh vết nâu lúa trong điều kiện nhà lưới}

Thí nghiệm được bố trí theo thể thức HTNN gồm 6 nghiệm thức (Bảng 1) và 4 lần lặp lại. Mỗi lặp lại là một chậu, 2 cây/chậu.

Bảng 1. Các nghiệm thức được sử dụng trong thí nghiệm nhà lưới

\begin{tabular}{ll}
\hline Tên nghiệm thức & Cách sử dụng \\
\hline PT5 & Phun dịch trích tỏi 2\% lên tán lá ở 5 ngày trước lây bệnh (NTLB) \\
PT1 & Phun dịch trích tỏi $2 \%$ lên tán lá ở 1 NTLB \\
PS1 & Phun dịch trích tỏi 2\% lên tán lá ở 1 NSLB \\
PS5 & Phun dịch trích tỏi 2\% lên tán lá ở 5 NSLB \\
Đối chứng dương & Phun Tilt Super 300EC lên tán lá ở 5 NSLB \\
Đối chứng nước cất & Phun nước cất thanh trùng, có thêm $0,2 \%$ Tween 20 \\
\hline
\end{tabular}

PT5: Phun dịch trích tỏi 2\% lên tán lá ở 5 NTLB; PT1: Phun dịch trích tỏi 2\% lên tán lá ơ 1 NTLB; PS1: Phun dịch trích tỏi $2 \%$ lên tán lá ở 1 NSLB; PS5: Phun dịch trích tỏi $2 \%$ lên tán lá ở 5 NSLB

Dịch trích thực vật và nấm Curvularia sp. được chuẩn bị tương tự thí nghiệm trước đó. Loại thuốc Tilt Super 300EC (150 g/L Difenoconazole + 150 $\mathrm{g} / \mathrm{L}$ Propiconazole, Syngenta) được sử dụng theo nồng độ khuyến cáo với liều lượng $15 \mathrm{~mL}$ pha loãng ra bình $16 \mathrm{~L}$, tương ứng $0,9375 \mathrm{~mL} / \mathrm{L}$ nước.

$\mathrm{Ba} \mathrm{kg}$ đất được cân và cho vào mỗi chậu nhựa có đường kính $30 \mathrm{~cm}$, bón lót trước khi gieo. Hạt lúa Jasmine 85 được ngâm trong nước 3 sôi, 2 lạnh, trong 30 phút. Hạt lúa tiếp tục được ngâm 24 giờ trong nước cất, rồi ủ 48 giờ trong giấy thấm ướt, để trong điều kiện tối. Bốn hạt lúa nảy mầm tốt được gieo vào 4 góc trong 1 chậu nhựa đã chuẩn bị đất. Ở 5 ngày, loại bỏ 2 cây lúa, để lại 2 cây lúa/chậu. Cách bón phân được áp dụng công thức phân bón $120 \mathrm{~N}$ $40 \mathrm{P}_{2} \mathrm{O}_{5}-30 \mathrm{~K}_{2} \mathrm{O}$ (Nguyễn Ngọc Đệ, 2008). Phân được hòa nước và tưới đều cho mỗi chậu, mực nước trên chậu khoảng $2 \mathrm{~cm}$, chăm sóc và bảo vệ cây lúa không bị tấn công bởi sâu bệnh. Khi cây lúa có 6 lá phát triển đầy đủ (tương đương 20-21 NSKG) thì 
dùng viết đánh dấu lá thứ 5 và thứ 6 , và tiến hành lây bệnh nhân tạo. Bào tử nấm Curvularia $\mathrm{sp}$. được phun $3 \mathrm{~mL} / \mathrm{chậu}$ với mật số 50.000 bào tử $/ \mathrm{mL}$, có thêm $0,2 \%$ Tween 20 . Các chậu sau khi phun huyền phù nấm được để trong phòng lây bệnh nhân tạo, ủ 24 giờ trong tối, $25^{\circ} \mathrm{C}$, ẩm độ khoảng $95 \pm 3 \%$. Sau đó, các chậu lúa được chuyển ra nhà phun sương, 30 phút/lần phun, che mát $50 \%$ nhằm giúp cho bệnh phát triển (Elamawi \& El-Shafey, 2013).

Vào 7 và 14 NSLB, ở hai lá lúa đã đánh dấu, chiều dài, chiều rộng lá và số lượng vết bệnh ở từng cấp được ghi nhận dựa vào bảng phân cấp đánh giá của Pinnschmidt et al. (2010). Các thông số cần tính bao gồm diện tích nhiễm bệnh $\left(\mathrm{mm}^{2}\right)$ (công thức 1), tỉ lệ diện tích lá nhiễm bệnh (\%) (công thức 2 ) và HQGB so với đối chứng (công thức 4).

$$
\operatorname{HQGB}(\%)=\left[\frac{\left(T_{L D T L N B_{j d c}}-T L D T L N B_{j}\right)}{T L D T L N B_{j d c}}\right] x 100 \%
$$

Trong đó, TLDTLNB jdc $_{\text {jà tỉ lệ diện tích lá nhiễm }}$ bệnh đối chứng thứ $\mathrm{j}(\mathrm{j}=5-6)$, TLDTLNB $\mathrm{j}$ là tỉ lệ diện tích lá nhiễm bệnh thứ $\mathrm{j}$. Thí nghiệm được lặp lại hai lần.

\subsection{Phương pháp phân tích số liệu}

Số liệu thô được xử lý bằng Microsoft Excel. Phân tích ANOVA và kiểm định Duncan được thực hiện để so sánh sự khác biệt giữa trung bình nghiệm thức bằng phần mềm MSTATC.

\section{KÊT QUẢ VÀ THẢO LUẬN}

\section{1. Đặc điểm bào tử và đĩa áp của các chủng nấm Curvularia}

Trong điều kiện phòng thí nghiệm $\left(28-30^{\circ} \mathrm{C}, 60-\right.$ $80 \% \mathrm{RH})$, tản nấm phát triển trong môi trường PDA có màu xám đen đến đen, đường kính khuẩn ty nấm đạt kích thước $8,75 \pm 0,25 \mathrm{~cm}$ ở 5 ngày sau khi cấy (NSKC). Khuẩn ty nấm trên môi trường PDA có dạng tròn, tâm màu xám đen hay đen đậm, có vòng đồng tâm.

Mỗi chủng nấm có hình dạng và kích thước bào tử trung bình không thay đổi nên được chọn làm tiêu chuẩn cơ bản để phân nhóm Curvularia sp. trên lúa (Bảng 2, Hình 1). Kết quả này phù hợp với nghiên cứu của Liu et al. (2016).

\section{Bảng 2. Phân nhóm nấm Curvularia sp. gây bệnh vết nâu trên lúa}

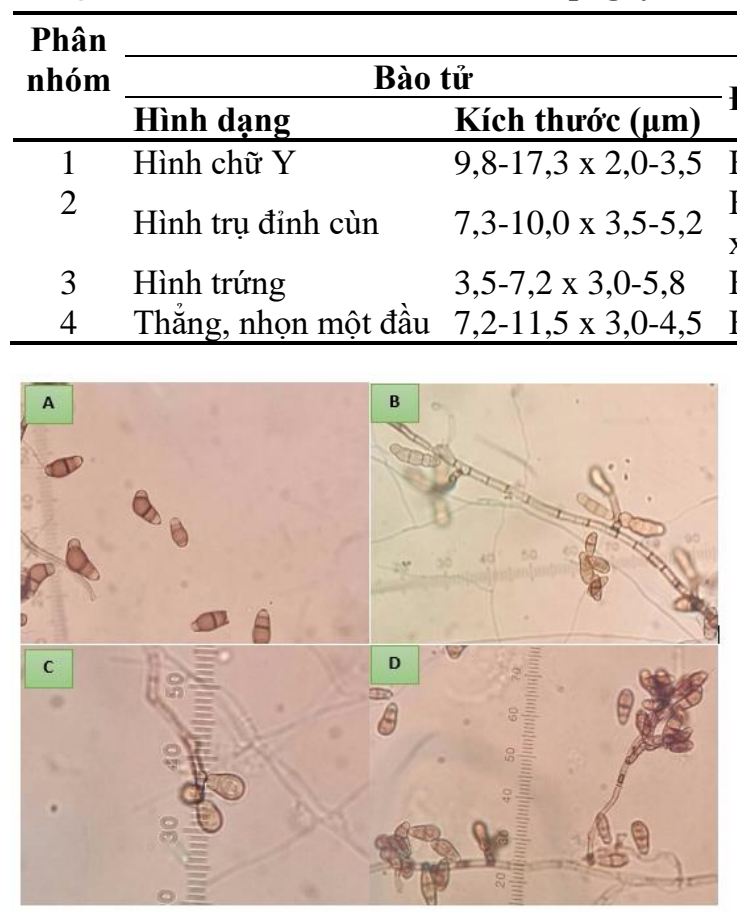

Hình 1. Hình dạng bào tử của nấm Curvularia sp. từ các nguồn nấm

A: Hình chũ $Y$, B: Hình trụ đỉnh cùn, C: Hình trúng, D: Thẳng, nhọn một đầu
Đăcc điểm Đĩa áp

Hạch nấm và gai cứng

Hình chùy, trứng

Hình chùy, trứng, xẻ thùy

Hình trứng

Hạch nấm màu đen và có gai cứng

Hạch nấm màu đen và có gai cứng

Hạch nấm màu đen và có gai cứng Hạch nấm màu đen và có gai cứng

Nấm có thể hình thành cấu trúc đĩa áp để xâm nhiễm. Đĩa áp có thể hình thành từ sợi nấm hoặc có thể hình thành từ bào tử. Trong nghiên cứu này, ba dạng đĩa áp đã tìm được từ năm chủng nấm Curvularia sp. là (1) dạng chùy (chủng 2, 3, 4), (2) dạng trứng (chủng 5), (3) dạng xẻ thùy (chủng 1, 2, 3, 4) (Hình 2).

Kết quả đánh giá nhanh tính độc của các chủng nấm Curvularia ghi nhận ở lá 5 , chủng nấm 1 và 2 có tỉ lệ diện tích lá bệnh khoảng 3,03-3,34\%, cao hơn có ý nghĩa so với chủng 3,4 và 5 (khoảng 1,89 $2,47 \%$ ). Ở lá lúa 6 , diện tích lá bệnh của chủng nấm 2 và 3 khoảng 3,01-3,73\%, cao hơn có ý nghĩa so với diện tích lá bệnh của ba chủng nấm 1,4 và 5 (2,03-2,87\%) (Bảng 3). Do đó, chủng nấm Curvularia số 2 được chọn để thực hiện các thí nghiệm tiếp theo. 


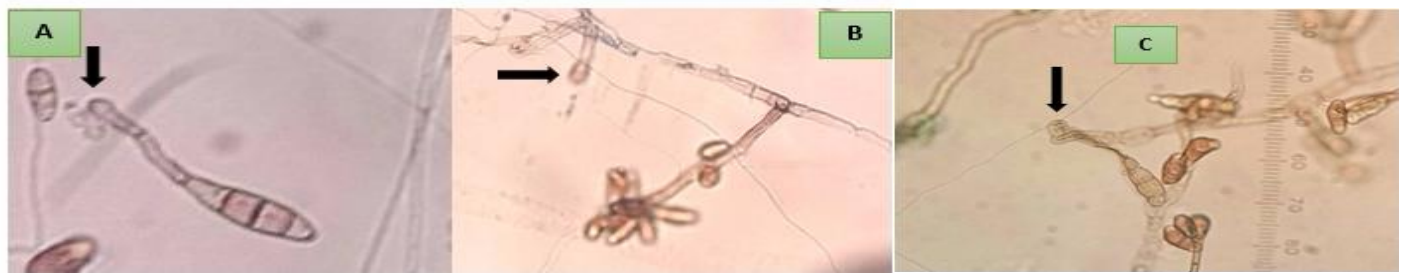

Hình 2. Các dạng đĩa áp của nấm Curvularia sp. trên lúa từ các nguồn nấm
A: Hình chùy
B: Hinh trúng
C: Dạng xẻ thùy

Bảng 3. Tỷ lệ diện tích lá bệnh trên lúa ở 7 ngày sau khi lây bệnh

\begin{tabular}{lrr}
\hline Nghiệm thức & Lá 5 $^{\mathbf{1 /}}$ & \multicolumn{1}{c}{ Lá 6 $^{\mathbf{1}}$} \\
\hline Curvularia chủng 1 & $3,03 \mathrm{a}$ & $2,87 \mathrm{~b}$ \\
Curvularia chủng 2 & $3,34 \mathrm{a}$ & $3,73 \mathrm{a}$ \\
Curvularia chủng 3 & $2,47 \quad \mathrm{~b}$ & $3,01 \mathrm{a}$ \\
Curvularia chủng 4 & $2,21 \quad \mathrm{~b}$ & $2,77 \mathrm{~b}$ \\
Curvularia chủng 5 & $1,89 \quad \mathrm{~b}$ & $2,03 \mathrm{~b}$ \\
\hline Mức ý nghĩa & $* *$ & $* *$ \\
CV $(\%)$ & 18,91 & 10,53 \\
\hline
\end{tabular}

Ghi chú: ${ }^{1 / C a ́ c}$ trung bình trong cùng một cột được theo sau bởi các chũ cái giống nhau thi không khác biệt ý nghĩa thống kê Duncan, **: khác biệt ở mức ý nghĩa 1\%.

\subsection{HQDT thực vật đối với nấm Curvularia trong điều kiện in vitro}

Bảng 4. Hiệu quả dịch trích $(\%)$ với nấm Curvularia qua các ngày sau khi đặt khuẩn ty

\begin{tabular}{|c|c|c|c|}
\hline \multirow[t]{2}{*}{ Nghiệm thức } & \multicolumn{3}{|c|}{$\begin{array}{l}\text { Hiệu quả (\%) qua các thò̀i } \\
\text { điểm (NSKC) }{ }^{1 /}\end{array}$} \\
\hline & $1^{2 /}$ & $3^{2 /}$ & $5^{2 \prime}$ \\
\hline Tỏi 2\% & $7,14 \mathrm{~b}$ & $8,13 \mathrm{a}$ & 8,39 \\
\hline Húng quế $2 \%$ & $0,00 \quad \mathrm{c}$ & $0,00 \mathrm{~b}$ & 0,00 \\
\hline Gừng 2\% & $18,57 \mathrm{a}$ & $0,77 \mathrm{~b}$ & 2,39 \\
\hline Đối chứng & $0,00 \quad \mathrm{c}$ & $0,00 \mathrm{~b}$ & 0,00 \\
\hline Mức ý nghĩa & $* *$ & $*$ & ns \\
\hline $\mathrm{CV}(\%)$ & 25,52 & 42,83 & 87,16 \\
\hline
\end{tabular}

Ghi chú: Các trung bình trong cùng một cột được theo sau bởi các chũ cái giống nhau thì không khác biệtý nghĩa thống kê Duncan, **: khác biệt ở mức ý nghĩa 1\%, *: khác biệt ở mức ý nghĩa 5\%, ns: không khác biệt ờ múc ý nghĩa 5\%.

Kết quả khảo sát HQDT của các nghiệm thức đối với nấm Curvularia sp. cho thấy đa số các nghiệm thức đều thể hiện hiệu quả ức chế tăng dần theo thời gian và ở nhiều mức độ khác nhau tùy vào nghiệm thức. Ở thời điểm 1 NSĐKT, nghiệm thức gừng $2 \%$ và tỏi $2 \%$ có hiệu quả ức chế lần lượt là $18,57 \%$, $7,14 \%$ và cao hơn có ý nghĩa ở mức $1 \%$ so với nghiệm thức đối chứng. Đến thời điểm 3 NSĐKT, HQDT của nghiệm thức tỏi $2 \%$ cao nhất $(8,13 \%)$ và khác biệt ý nghĩa so với nghiệm thức đối chứng ở mức 5\%. Tại thời điểm $5 \mathrm{NSĐKT,} \mathrm{các} \mathrm{nghiệm} \mathrm{thức}$ dịch trích không thể hiện hiệu quả dịch trích. Như vậy, HQDT của nghiệm thức tỏi $2 \%$ cao nhất và khác biệt có ý nghĩa so với nghiệm thức đối chứng và tăng dần ở giai đoạn 1-3 NSĐKT (từ 7,14\% lên $8,13 \%$ ). HQDT của nghiệm thức gừng $2 \%$ ở thời điểm 1 NSĐKT cao nhất $18,57 \%$ nhưng đến thời điểm 3 NSĐKT thì giảm còn $0,77 \%$ và khác biệt không có ý nghĩa so với đối chứng ở thời điểm này (Bảng 4, Hình 3).

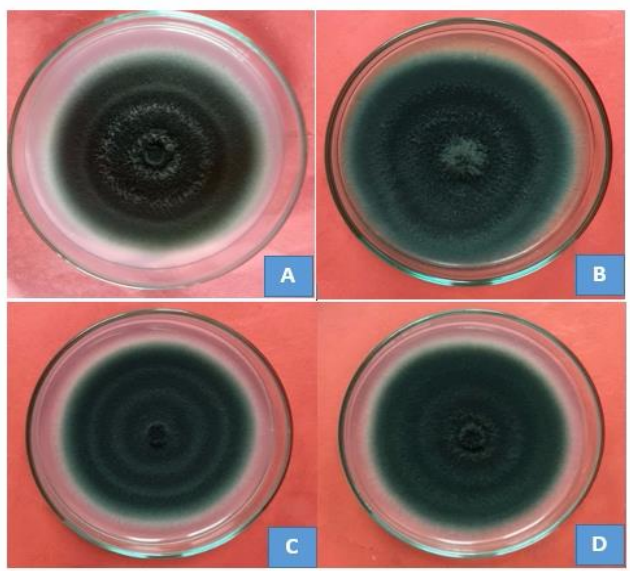

Hình 3. Hiệu quả ức chế của dịch trích với nấm Curvularia tại thời điểm 5 NSKC trong điều kiện phòng thí nghiệm

A: Nghiệm thức tỏi $2 \%, \quad B$ : Nghiệm thức húng quế $2 \%$,

C: Nghiệm thức gùng 2\%, D: Nghiệm thức đối chứng (nước cất)

Các nghiệm thức gồm tỏi $2 \%$ và gừng $2 \%$ có khả năng ức chế sự hình thành bào tử nấm Curvularia và khác biệt ý nghĩa ở mức 5\%. Trong đó, nghiệm thức tỏi $2 \%$ gây ức chế hình thành bào tử (mật số trung bình 5,12 ) thấp hơn có ý nghĩa so với nghiệm thức đối chứng $(8,72)$ và các nghiệm thức dịch trích còn lại (húng quế $2 \%$ là 9,16 , gừng $2 \%$ là 5,96 ). Về hiệu quả ức chế, nghiệm thức tỏi $2 \%$ thể hiện khả năng ức chế bào tử cao nhất $41,28 \%$, kế tiếp là 
nghiệm thức gừng $2 \%$ có hiệu quả ức chế là $31,65 \%$, đều khác biệt ý nghĩa so với đối chứng (Bảng 5).
Bảng 5. Hiệu quả ức chế (\%) với mật số bào tử nấm Curvularia ở 5 ngày sau đặt khoanh nấm

\begin{tabular}{lrr}
\hline Nghiệm thức & $\begin{array}{r}\log _{10} \text { của mật số } \\
\text { bào tử (bào tử) }\end{array}$ & $\begin{array}{r}\text { Hiệu quả chế (\%) } \\
\text { ưc }\end{array}$ \\
\hline Tỏi $2 \%$ & $5,12 \mathrm{c}$ & $41,28 \mathrm{a}$ \\
Húng quế $2 \%$ & $9,16 \mathrm{a}$ & $0,00 \mathrm{~b}$ \\
Gừng $\%$ & $5,96 \mathrm{bc}$ & $31,65 \mathrm{a}$ \\
Đối chứng & $8,72 \mathrm{ab}$ & $0,00 \mathrm{~b}$ \\
\hline Mức ý nghĩa & $*$ & $*$ \\
CV $(\%)$ & 29,51 & 38,62 \\
\hline
\end{tabular}

Ghi chú: Các trung bình trong cùng một cột được theo sau bởi các chũ cái giống nhau thì không khác biệt ý nghĩa thống kê Duncan ở mức 5\%.

Như vậy, các nghiệm thức tỏi $2 \%$ và gừng $2 \%$ có khả năng ức chế sự phát triển của sợi nấm và sự hình thành bào tử cao hơn nghiệm thức húng quế $2 \%$. Riêng nghiệm thức tỏi $2 \%$ có khả năng ức chế sự phát triển của khuẩn ty nấm cao hơn nghiệm thức gừng $2 \%$ nên được chọn để thực hiện thí nghiệm ngoài nhà lưới. Điều này phù hợp với kết quả một số nghiên cứu trước đây. Trong điều kiện vi vitro, dịch trích tỏi $5 \%$ thể hiện hiệu quả ức chế sự phát triển nấm Pythium trên cà chua ở mức $41 \%$ (Alhussaen et al., 2011). Theo nghiên cứu của Fani et al. (2007), trong chiết xuất tỏi có allicin mang hoạt tính ức chế trên nhiều loại nấm và vi khuẩn gây nhiều bệnh khác nhau. Nghiên cứu của Aala et al. (2014) cho thấy sợi nấm Trichophyton rubrum sau khi xử lý bằng allicin chiết xuất từ tỏi $(12,5 \mu \mathrm{g} / \mathrm{mL})$ đã làm tan rã và suy giảm các bộ phận tế bào chất, phân hủy màng tế bào và thành tế bào, và làm hủy hoại sợi nấm.

\subsection{HQDT thực vật đối với bệnh vết nâu lúa trong điều kiện nhà lưới}

Khả năng ức chế bệnh khi phun dịch trích tỏi $2 \%$ được đánh giá và ghi nhận tại thời điểm 7 và 14 NSLB (tương đương 28 và $35 \mathrm{NSKG)} \mathrm{(Bảng} 6$ và 7). Ở thời điểm 7 NSLB, kết quả được trình bày trong Bảng 6 cho thấy các nghiệm thức đều có khả năng làm giảm bệnh và có khác biệt ý nghĩa ở mức
$1 \%$ với nghiệm thức đối chứng. Trong đó, nghiệm thức PS1 cho tỉ lệ diện tích nhiễm bệnh (TLDTNB) thấp nhất (TLDTNB lá 5 , lá 6 , trung bình hai lá lần lượt là $1,27,1,54,1,41 \%$ ) và có ý nghĩa so với nghiệm thức đối chứng nước cất (TLDTNB lá 5 , lá 6 , trung bình hai lá lần lượt là $3,49,4,64,4,06 \%$ ) và HQGB cao nhất so với nghiệm thức đối chứng (HQGB lá 5, lá 6, trung bình hai lá lần lượt là 63,61, $66,81,65,21 \%$ ). Kế đến là nghiệm thức $\mathrm{PT} 1$ có HQGB trung bình hai lá là $45,95 \%$ (lá 5 , lá 6 lần lượt là $36,10,55,81 \%$ ) cao hơn có ý nghĩa so với nghiệm thức đối chứng nước cất. Song song đó là nghiệm thức đối chứng dương phun thuốc Tilt Super 300EC ở 5 NSLB cho hiệu quả với TLDTNB trung bình hai lá là $1,88 \%$ (lá 5 , lá 6 lần lượt là $2,23,1,54 \%$ ) và HQGB trung bình hai lá là $51,45 \%$ (lá 5 , lá 6 lần lượt là 36,$10 ; 66,81 \%$ ) khác biệt có ý nghĩa so với nghiệm thức đối chứng nước cất. Còn nghiệm thức PT5 và nghiệm thức PS5 cho TLDTNB thấp và HQGB cao với nghiệm thức đối chứng nhưng không lớn, thể hiện khả năng hạn chế bệnh không cao ở thời điểm này. Ở thời điểm 14 NSLB, các nghiệm thức thể hiện rõ khả năng hạn chế bệnh và đều có khác biệt ý nghĩa ở mức $1 \%$ hay $5 \%$ tùy vào mỗi nghiệm thức so với nghiệm thức đối chứng (Bảng 7). Nghiệm thức PT1 và nghiệm thức PS1 thể hiện rõ khả năng hạn chế nấm bệnh nhất với TLDTNB (nghiệm thức PT1 có TLDTNB lá 5, lá 6 , trung bình hai lá lần lượt là 2,42, 2,15, 2,29\%; nghiệm thức PS1 có TLDTNB lá 5 , lá 6 , trung bình hai lá lần lượt là $2,83,1,53,2,18 \%$ ), thấp hơn có ý nghĩa so với nghiệm thức đối chứng nước cất (TLDTNB lá 5 , lá 6 , trung bình hai lá lần lượt là $4,51,5,27,4,89 \%$ ). HQGB của nghiệm thức PT1 (lá 5 , lá 6 , trung bình hai lá lần lượt là $46,34,59,20,52,77 \%$ ) và nghiệm thức PS1 (lá 5 , lá 6 , trung bình hai lá lần lượt là $37,25,70,96,54,11 \%$ ) cao hơn có ý nghĩa so với nghiệm thức đối chứng nước cất, tương đương với nghiệm thức đối chứng dương (TLDTNB lá 5 , lá 6 , trung bình hai lá lần lượt là 2,05, 2,08, 2,07\%, HQGB lá 5 , lá 6 , trung bình hai lá lần lượt là 54,54 , $60,53,57,54 \%$ ). Các nghiệm thức PT5 và nghiệm thức PS5 thì TLDTNT có chiều hướng tăng hơn so với thời điểm 7 NSLB nhưng HQGB vẫn cao hơn có ý nghĩa so với nghiệm thức đối chứng. 
Bảng 6. Tỷ lệ diện tích lá bệnh và HQGB (\%) trên lúa ở 7 ngày sau khi lây bệnh

\begin{tabular}{|c|c|c|c|c|c|c|}
\hline \multirow{2}{*}{ Nghiệm thức } & \multicolumn{2}{|c|}{ Lá $5^{1 /}$} & \multicolumn{2}{|c|}{ Lá $6^{1 /}$} & \multicolumn{2}{|c|}{ Trung bình ${ }^{1 /}$} \\
\hline & TLDTNB & HQGB & TLDTNB & HQGB & TLDTNB & HQGB \\
\hline$\overline{\text { PT5 }}$ & $3,19 \mathrm{a}$ & $8,59 \mathrm{~b}$ & $3,67 \mathrm{~b}$ & $20,90 \quad c$ & $3,43 \mathrm{ab}$ & 14,74 bc \\
\hline PT1 & $2,23 \mathrm{~b}$ & $36,10 \mathrm{a}$ & $2,05 \quad \mathrm{c}$ & $55,81 \mathrm{~b}$ & 2,14 abc & $45,95 \mathrm{ab}$ \\
\hline PS1 & $1,27 \mathrm{c}$ & $63,61 \mathrm{a}$ & $1,54 \mathrm{~d}$ & $66,81 \mathrm{a}$ & $1,41 \quad \mathrm{c}$ & $65,21 a$ \\
\hline PS5 & $3,66 \mathrm{a}$ & $0,00 \quad \mathrm{c}$ & $3,32 \mathrm{~b}$ & $28,44 \quad c$ & $3,49 \mathrm{ab}$ & $14,22 \mathrm{bc}$ \\
\hline Đối chứng dương & $2,23 \mathrm{~b}$ & $36,10 \mathrm{a}$ & $1,54 \mathrm{~d}$ & $66,81 \mathrm{a}$ & $1,88 \mathrm{bc}$ & $51,45 a$ \\
\hline Đối chứng nước cất & $3,49 \mathrm{a}$ & $0,00 \quad \mathrm{c}$ & $4,64 \mathrm{a}$ & $2,03 \mathrm{~d}$ & $4,06 \mathrm{a}$ & $1,02 \mathrm{c}$ \\
\hline Mức ý nghĩa & $* *$ & $* *$ & $* *$ & ** & $*$ & $*$ \\
\hline CV $(\%)$ & 12,62 & 20,48 & 13,05 & 12,14 & 29,80 & 52,89 \\
\hline
\end{tabular}

Ghi chú: ${ }^{1 / C a ́ c ~ t r u n g ~ b i ̀ n h ~ t r o n g ~ c u ̀ n g ~ m o ̣ ̂ t ~ c o ̣ ̂ t ~ đ u ̛ o ̛ ̣ c ~ t h e o ~ s a u ~ b o ̛ ̉ i ~ c a ́ c ~ c h u ̃ ~ c a ́ i ~ g i o ̂ ́ n g ~ n h a u ~ t h i ̀ ~ k h o ̂ n g ~ k h a ́ c ~ b i e ̣ ̂ t ~ y ́ ~ n g h i ̃ a ~}$ thống kê Duncan, **: khác biệt ở múc ý nghĩa 1\%, *: khác biệt ở múc ý nghĩa 5\%.

Bảng 7. Tỷ lệ diện tích lá bệnh (\%) và HQGB (\%) trên lúa ở 14 ngày sau khi lây bệnh

\begin{tabular}{|c|c|c|c|c|c|c|}
\hline \multirow{2}{*}{ Nghiệm thức } & \multicolumn{2}{|c|}{ Lá $5^{1 /}$} & \multicolumn{2}{|c|}{ Lá $6^{1 /}$} & \multicolumn{2}{|c|}{ Trung bình $^{1 /}$} \\
\hline & TLDTNB & HQGB & TLDTNB & HQGB & TLDTNB & HQGB \\
\hline PT5 & $4,52 \mathrm{~b}$ & $0,00 \quad \mathrm{~d}$ & $5,00 \mathrm{a}$ & $5,12 \mathrm{~b}$ & $4,26 \mathrm{ab}$ & $2,56 \mathrm{~cd}$ \\
\hline PT1 & $2,42 \mathrm{c}$ & $46,34 \mathrm{~b}$ & $2,15 \mathrm{c}$ & $59,20 \mathrm{a}$ & $2,29 \mathrm{bc}$ & $52,77 \mathrm{abc}$ \\
\hline PS1 & $2,83 \mathrm{c}$ & $37,25 \quad c$ & $1,53 \mathrm{~d}$ & 70,96 a & $2,18 \mathrm{c}$ & $54,11 \mathrm{ab}$ \\
\hline PS5 & $7,20 \mathrm{a}$ & $0,00 \quad \mathrm{~d}$ & $3,98 \mathrm{~b}$ & $24,47 \quad b$ & $5,59 \mathrm{a}$ & $12,24 \mathrm{bc}$ \\
\hline Đối chứng dương & $2,05 \mathrm{c}$ & $54,54 \mathrm{a}$ & $2,08 \mathrm{c}$ & $60,53 \mathrm{a}$ & $2,07 \mathrm{c}$ & $57,54 \mathrm{a}$ \\
\hline Đối chứng nước cất & $4,51 \mathrm{~b}$ & $0,00 \quad \mathrm{~d}$ & $5,27 \mathrm{a}$ & $0,00 \mathrm{c}$ & $4,89 \mathrm{a}$ & $0,00 \mathrm{~d}$ \\
\hline Mức ý nghĩa & $* *$ & * & $* *$ & $* *$ & $*$ & $*$ \\
\hline $\mathrm{CV}(\%)$ & 5,12 & 67,19 & 6,67 & 5,83 & 34,05 & 51,70 \\
\hline
\end{tabular}

Ghi chú: ${ }^{1 / C a ́ c ~ t r u n g ~ b i ̀ n h ~ t r o n g ~ c u ̀ n g ~ m o ̣ ̂ t ~ c o ̣ ̂ t ~ đ u ̛ o ̛ ̣ c ~ t h e o ~ s a u ~ b o ̛ ̉ i ~ c a ́ c ~ c h u ̃ ~ c a ́ i ~ g i o ̂ ́ n g ~ n h a u ~ t h i ̀ ~ k h o ̂ n g ~ k h a ́ c ~ b i e ̣ ̂ t ~ y ́ ~ n g h i ̃ a ~}$ thống kê Duncan, **: khác biệt ở múc ý nghĩa 1\%, *: khác biệt ở múc ý nghĩa 5\%.

Như vậy, nghiệm thức PS1 cho hiệu quả tốt hơn các nghiệm thức khác đối với bệnh vết nâu trong điều kiện nhà lưới, thể hiện qua chỉ tiêu TLDTNB và HQGB ở các thời điểm đã khảo sát. HQDT tỏi đối với nấm Curvularia trên lúa trong nghiên cứu này tương tự kết quả nghiên cứu với nấm Drechslera tritici-repetis, Bipolaris sorokiniana và Septoria tritici trên lúa mì (Perello et al., 2013), nấm Phytophthora trên cây thuốc lá (Wang et al., 2019) và các nấm gây hại hạt cây muồng hoa pháo (Calliandra callothyrsus) (Suharti et al., 2020). Wang et al. (2019) cho biết các nghiệm thức xử lý dịch trích tỏi giúp rễ cây thuốc lá đã lây nhiễm nhân tạo với Phytophthora mọc dài hơn (27,33-44,83 $\mathrm{mm})$, khác biệt có ý nghĩa so với nghiệm thức đối chứng nước cất $(19,50 \mathrm{~mm})$. Theo nghiên cứu của Yeasmin et al. (2012) và Nagella et al. (2014), tỏi chứa polyphenolic giúp tăng sự sinh trưởng của cây lúa kể cả trong điều kiện bất lợi. Tỏi có khả năng kháng nấm bệnh, giúp tăng sự nảy mầm của hạt lúa và tăng khả năng kháng bệnh của cây lúa. Bên cạnh đó, trong tỏi có chứa chất alixin rất dễ kết hợp với một axit amin có gốc SH là xystein để cho một hợp chất, giúp ức chế sự sinh sản của vi sinh vật (Đỗ Tất
Lợi, 2009). Điều này chứng tỏ dịch trích tỏi có khả năng ức chế sự phát triển của bệnh vết nâu trên lúa.

\section{KÊTT LUẬN VÀ ĐỀ NGHI!}

Kết quả ghi nhận nấm Curvularia sp. có bốn dạng bào tử và ba dạng đĩa áp. Trong điều kiện phòng thí nghiệm, dịch trích tỏi và gừng đều cho hiệu quả ức chể khuẩn ty và sự hình thành bào tử nấm Curvularia. Trong đó, dịch trích tỏi $2 \%$ cho hiệu quả cao nhất với đường kính khuẩn ty thấp nhất, hiệu quả ức chế cao nhất và khả năng ức chế bào tử cao hơn các dịch trích còn lại và đối chứng. Ở điều kiện nhà lưới, các kết quả cho thấy dịch trích tỏi $2 \%$ là loại dịch trích có hiệu quả giúp cây lúa chống lại bệnh vết nâu do nấm Curvularia sp. gây ra. Tùy vào thời điểm mà dịch trích tỏi $2 \%$ thể hiện khả năng kháng bệnh khác nhau. Trong đó, việc phun dịch trích tỏi $2 \%$ lên tán lá ở 1 NSLB thể hiện hiệu quả tốt so với các nghiệm thức xử lý khác.

Thành phần có trong các loại dịch trích sẽ được nghiên cứu để li trích và sử dụng hiệu quả nhất.

\section{TÀI LIÊU THAM KHẢO}

Aala, F., Yusuf, U. K., Nulit, R., \& Rezaie, S. (2014). Inhibitory effect of allicin and garlic extracts on 
growth of cultured hyphae. Iranian Journal of Basic Medical Sciences, 17(3), 150-154.

Akhsan, N., Sopialena, \& Fahrizal. (2019). Plant resistance to leaves and their effects on paddy rice production in Kutai Barat District, East Kalimantan Province, Indonesia. Asian Journal of Agriculture, 3(2), 41-46.

Alhussaen, K., Hussein, E. I., Al-Batayneh, K. M., Al-Khatib, M., Al Khateeb, W., Jacob, J. H., Shatnawi, M. A., Khashroum, A., \& Hegazy, M. I. (2011). Identification and controlling Pythium sp. infecting tomato seedlings cultivated in Jordan valley using garlic extract. Asian Journal of Plant Pathology, 5(2), 84-92.

Atlas, R. M. (Ed.) (2010). Handbook of Microbiological Media (4th $e d$.). CRC Press. 771-779.

Đỗ Tất Lợi (Ed.) (2009). Nhũng cây thuốc và vị thuốc Việt Nam. Nhà xuất bản Y Học.

Elamawi, R. M. A., \& El-Shafey, R. A. S. (2013). Inhibition effect of silver nanoparticles against rice blast disease caused by Magnaporthe grisea. Egypt J. Agric. Res., 94(4), 1271-1283.

Fani, M. M., Kohanteb, J., \& Dayaghi, M. (2007). Inhibitory activity of garlic (Allium sativum) extract on multidrug-resistant Streptococcus mutans. Journal of Indian Society of Pedodontics and Preventive Dentistry, 25(4), 164-168.

Lê Thanh Toàn, \& Thị Sử (2020). Thành phần nấm gây lem lép hạt lúa tại Hòn Đất - Kiên Giang và khảo sát hiệu quả của một số dịch trích thực vật đối với nấm Curvularia sp. và Fusarium sp. hại hạt lúa. Tạp chí Khoa học Đại học An Giang, 24(1), 68-75.

Lê Văn Cương, Đoàn Tấn Cảnh, \& Hoàng Kim Toản (2018). Sinh trưởng, phát triển, năng suất và chất lượng của một số giống lúa thuần tại Quãng Ngãi. Tạp chi Khoa hoc Đại hoc Huế: Nông nghiệp và Phát triển nông thôn, 127(3B), 135-148.

Liu, T., Wang, Y., Ma, B., Hou, J., Jin, Y., Zhang, Y., Ke, X., Tai, L., Zuo, Y., \& Dey, K. (2016). $\mathrm{Clg} 2 \mathrm{p}$ interacts with clf and clurase to regulate appressorium formation, pathogenicity and conidial morphology in Curvularia lunata. Scientific Reports, 6(4), 2404-2450.

Nagella, P., Thiruvengadam, M., Ahmad, A., Yoon, J. Y., \& Chung, I. M. (2014). Composition of polyphenols and antioxidant activity of garlic bulbs collected from different locations of Korea. Asian Journal of Chemistry, 26(3), 897-902.

Nguefack, J., Leth, V., Dongmo, J. B. L., Torp, J., Zollo, P. H. A., \& Nyasse, S. (2008). Use of three essential oils as seed treatments against seed borne fungi of rice (Oryza sativa L.).
American-Eurasian J. Agric. and Enviroment Sci., 4(5), 554-556.

Nguyễn Ngọc Đệ (Ed.). (2008). Giáo trình cây lúa. Khoa Nông nghiệp, Trường Đại học Cần Thơ.

Ortega, S. F., Ferrocino, I., Adams, I., Silvestri, S., Spadaro, D., Gullino, M. L., \& Boonham, N. (2020). Monitoring ands of aerial mycobiota of rice paddy through DNA Metabarcoding and qPCR. Journal of Fungi, 6(372), 1-23.

Perello, A., Noll, U., \& Slusarenko, A. J. (2013). In vitro efficacy of garlic extract to control fungal pathogens of wheet. Journal of Medicinal Plants Research, 7(24), 1809-1817.

Pinnschmidt, H. O., Teng, P. S., Bonman, J. M., \& Kranz, J. (1993). New assessment key for leaf blast. IRRN, 18, 45-46.

Phan Thị Hồng Thúy (2009). Khảo sát khả năng hạn chế bệnh cháy lá và đốm nâu trên lúa khi xủ lí với ba loại dịch trich thưc vật trong điều kiện nhà luới. Luận văn Tốt nghiệp Thạc sỹ, Trường Đại học Cần Thơ.

Suharti, T., Nugraheni, Y. M. M. A., Suita, E., \& Sumarni, B. (2020). Effect of plant extracts and chemical fungicide on viability and percentage of seed-borne fungal infection on calliandra (Calliandra callothyrsus) seed. IOP Conf. Series: Earh and Environmental Science, 533(012040), 1-8.

Tann, H., \& Soytong, K. (2017). Biological control of brown leaf spot disease caused by Curvularia lunata and field application method on rice variety IR66 in Cambodia. AGRIVITA Journal of Agricultural Science, 39(10), 111-117.

Tổng cục Thống kê. (2020). Các báo cáo phân tích và dụ báo thống kê năm 2019. Tổng cục Thống kê Việt Nam. https://www.gso.gov.vn/wpcontent/uploads/2020/11/Ky-yeu-2019.pdf.

Wang, Y., Wei, K., Han, X., Zhao, D., Zheng, Y., Chao, J., Gou, J., Kong, F., \& Zhang, C. S. (2019). The antifungal effect of garlic essential oil on Phytopthora nicotianae and the inhibitory component involved. Biomolecules, 9(632), 1-12.

Wijedasa, M. H., \& Liyanapathirana, L. V. C. (2012). Evaluation of an alternative slide culture technique for the morphological identification of species. Sri Lanka Journal of Infectious Disease, 2, 47-52.

Yeasmin, F., Ashrafuzzaman, M., \& Hossain, I. (2012). Effects of garlic extract, allamanda leaf extract and provax-200 on seed borne fungi of rice. The Agriculturists, 10(1), 46-50. 